\title{
Frying Performance of High Oleic Oil Enriched in Biophenols during Discontinuos and Prolonged Thermal Treatment
}

\author{
R. Romano*, N. Manzo, L. Le Grottaglie, A. Fiore, V. Fogliano \\ Dip. to Agraria-Università Degli Studi di Napoli “Federico II”-Via Università, Portici, Italy. \\ Email: *rafroman@unina.it \\ Received May $16^{\text {th }}, 2013$; revised June $16^{\text {th }}, 2013$; accepted June $24^{\text {th }}, 2013$ \\ Copyright (C) 2013 R. Romano et al. This is an open access article distributed under the Creative Commons Attribution License, \\ which permits unrestricted use, distribution, and reproduction in any medium, provided the original work is properly cited.
}

\begin{abstract}
Biophenols are potent natural antioxidants that protect food quality by preventing oxidative deterioration of lipids. During heat treatment this protective rule prevents oxidation caused by many factors, as high temperature reached, presence of oxygen and water contained in food matrix. The aim of this study was to evaluate the frying performance of high oleic oil enriched in biophenols, comparing its thermal stability with those of high oleic oil (control sample) during thermo-oxidation and deep fat frying process. Positive effects when biophenols were added to oil were found: lower acidity levels, lower TPC values during the first 16 hours of heat treatment, absence of short chain fatty acids (C8:0) until $24 \mathrm{~h}$ of thermo-oxidation treatment and detection of lower acrylamide content in French friesrespect to those fried in the control oil.
\end{abstract}

Keywords: Biophenols; High Oleic Oil; Deep Fat Frying; Olive Mill Waste Water

\section{Introduction}

Deep fat frying is one of the oldest cooking methods, dating back to 1600 A.C. in China [1]. This method, consisting in the immersion of the food in oil bath at temperature of $150^{\circ} \mathrm{C}-190^{\circ} \mathrm{C}$ [2], provides many advantages, like very efficient heat transferring, crispy texture and typical flavor [3].

During frying, the oil undergoes a complex series of harmful reactions, such as hydrolysis and oxidation due to oxygen (from air and food), food moisture and high temperature. Moreover, during frying, toxic compoundssuch as acrylamide can be produced [4].

Extra virgin olive oils are rich in phenolic compounds, such as hydroxytyrosol and oleuropein, which give high stability to oil, because they are powerful antioxidants [5].

Seed oils are generally poorer of phenolic compounds than olive oils $[6,7]$. The aim of this study was to evaluate oxidation stability of high oleic oil enriched in biophenols, comparing its performance with that of the same oil where no phenols were added, during discontinuous and prolonged thermal treatment.

${ }^{*}$ Corresponding author.

\section{Materials and Methods}

The oil used (MIX) was a blend of rapeseed oil (60\%), sunflower oil (38\%), and grape seed oil $(2 \%)$. The oil and frozen French fries were obtained by commercial Italian market.

Biophenols were obtained by spray drying of olive mill waste water (OMWW) resulting from extravirginolive oil production (Carolea variety, CROP 2011).

\subsection{Preparation of Oil Enriched in Biophenols}

$8 \mathrm{~g}$ of powder enriched in biophenols were dissolved in $10 \mathrm{ml}$ of water. Then $30 \mathrm{ml}$ of oil were added and shaken for 5 minutes with the aqueous solution. Oil was separated by centrifugation ( $6000 \mathrm{rpm}$ for $5 \mathrm{~min}$ ). Other 30 $\mathrm{ml}$ of oil were added to residual aqueous solution, shaken and then oil was separated as said above. This procedure was repeated several times in order to accumulate the required amount of oil enriched in biophenols.

The oil control (MIX C), where no biophenols were added, and oil enriched in biophenols (MIX P) were subjected to thermo-oxidation and to frying process with frozen pre-fried potatoes, according to the conditions described in [8]. Briefly, the heat treatment was con- 
ducted for $8 \mathrm{~h} /$ die for 6 dies at $180^{\circ} \mathrm{C} \pm 5^{\circ} \mathrm{C}$.

\subsection{Analytical Methods}

The samples were subjected to the following determinations:

- Total Biophenols (TB) by Folin-Ciocalteau method, after hydroalcolic extraction [9].

- Biophenols identification by HPLC/DAD:

$7 \mathrm{~g}$ of oil were extracted with $7 \mathrm{ml}$ of $\mathrm{MeOH}: \mathrm{H}_{2} \mathrm{O}$ 80:20 for three times. The extract was concentrated and then $7.5 \mathrm{ml}$ of acetonitrile and $7.5 \mathrm{ml}$ of hexane were added. The sample was evaporated, filtered on $0.2 \mu \mathrm{m}$ filter and injected. Biophenols analysis was carried out using an LC Agilent 1100 series (Palo Alto, CA) equipped with an online degasser, a quaternary pump and a diode array detector. The separation was performed by a Prodigy $5 \mathrm{u}$ ODS (3) $100 \mathrm{~A}$ (Phenomenex) $(250 \mathrm{~mm} \times 4.6 \mathrm{~mm}, 5$ $\mu \mathrm{m})$. The mobile phase A consisted in $3 \%$ trifluoroacetic acid (TFA) in $\mathrm{H}_{2} \mathrm{O}$, while mobile phase $\mathrm{B}$ consisted in acetonitrile-MeOH 80:20. HPLC conditions were the followings: 0.01 - $45 \mathrm{~min}, 5 \%$ - 98\% B; 45 - $47 \mathrm{~min}, 98 \%$ $5 \% \mathrm{~B} ; 47-50 \mathrm{~min}, 5 \% \mathrm{~B} ; 50-50 \mathrm{~min}, 5 \%-0 \% \mathrm{~B}$. The flow rate was set at $1 \mathrm{ml} / \mathrm{min}$, injection volume was 20 $\mu \mathrm{L}$ and detection was performed by monitoring the signal at 230 and $280 \mathrm{~nm}$. Peaks were identified by comparison of retention times with those of pure standard or with the spectral UV-Vis suggested by literature.

- Free Fatty Acids (FFA), Peroxide Value (PV), Total Polar Compounds (TPC) and Fatty Acid Composition, according to the method described in [8].

The samples were analyzed at $0,8,16,24,32,40$ and 48 hours.

- Determination of French fries acrylamide content

Acrylamide was measured according to procedure described in [10]. The freeze dried potato were ground in a knife mill Grindomix 200 (Retsch, Haan, Germany). One gram of powder was weighed; $9.9 \mathrm{~mL}$ of deionized water were added in a $15 \mathrm{~mL}$ centrifuge tube along with 500 $\mu \mathrm{L}$ of Carrez reagent potassium salt, $500 \mu \mathrm{L}$ of Carrez reagent zinc salt and $100 \mu \mathrm{L}$ of internal standard [2,3,3$\mathrm{d}_{3}$ ]-acrylamide $(20 \mu \mathrm{g} / \mathrm{mL}$ to achieve a final concentration of $90 \mathrm{ng} / \mathrm{mL}$ ). The tubes were shaken vigorously for $1 \mathrm{~min}$. The resulting mixture was centrifuged at $2700 \mathrm{~g}$ for $10 \mathrm{~min}$ at $4^{\circ} \mathrm{C}$. The supernatant was then collected in a $20 \mathrm{~mL}$ volumetric flask, and two further extractions were performed using $5 \mathrm{~mL}$ of deionized water. Finally, the pellets were discarded, and the supernatants were filtered through a $0.45 \mu \mathrm{m}$ nylon filter. Two milliliters of supernatants were collected and passed through an Oasis HLB cartridge (Waters, Milford, MA, USA) previously activated with $1 \mathrm{~mL}$ of methanol and $1 \mathrm{~mL}$ of deionized water; the first eight droplets of the effluent were discarded to prevent any dilution of the sample, and the fol- lowing droplets were collected; $20 \mu \mathrm{L}$ of the final test solution were injected onto the LC column for quantification by LC-MS/MS. Identification and quantitative determination of acrylamide and [2,3,3- $\left.\mathrm{d}_{3}\right]$-acrylamide were carried out using an API 2000 triple-quadrupole mass spectrometer (Applied Biosystems, Carlsbad, CA, USA) coupled to a ion spray interface, equipped with an HPLC binary micropump series 200 (Perkin-Elmer, USA). Chromatographic separation of acrylamide and $\left[2,3,3-\mathrm{d}_{3}\right]$-acrylamide was achieved through an Inertsil column, $25 \times 0.46 \mathrm{~cm}, 5 \mu \mathrm{m}$ (GLSciences, Torrance, CA, USA), the mobile phases were A: $0.1 \%$ formic acid and B: $0.1 \%$ formic acid in methanol and the following gradient elution was applied: $0-3 \mathrm{~min}, 100 \% \mathrm{~A} ; 3-8 \mathrm{~min}$, $93 \% \mathrm{~A} ; 8-12 \mathrm{~min}, 100 \%$, at a flow rate of $0.800 \mu \mathrm{L} / \mathrm{min}$, whereof $200 \mu \mathrm{L}$ was split into the ion source. The quantification was carried out in multiple reaction monitoring (MRM) at $\mathrm{m} / z$ ratios of 72 and 75 for acrylamide and $\left[2,3,3-\mathrm{d}_{3}\right]$-acrylamide, respectively. Specific molecular fragments corresponding to $\mathrm{m} / \mathrm{z} 55$ and 44 and $\mathrm{m} / \mathrm{z} 58$ and 44 were also monitored. The daughter ions were obtained through fragmentations with the following specific conditions: the source temperature was set at $350^{\circ} \mathrm{C}$, nitrogen was used as nebulizer gas at a flow rate of $12 \mathrm{~L} / \mathrm{h}$, and the needle and cone voltages were set at $3.0 \mathrm{kV}$ and $100 \mathrm{~V}$, respectively. Under the above-mentioned chromatographic conditions the acrylamide and its corresponding isotope standard eluted at $7.4 \mathrm{~min}$. Acrylamide was quantified using a linear calibration curve built with specific solutions of acrylamide and [2,3,3-d $\left.\mathrm{d}_{3}\right]$-acrylamide dissolved in water $(50-500 \mathrm{ng} / \mathrm{mL})$. The LOD (limit of determination) and LOQ (limit of quantification) were, respectively, 10 and $30 \mathrm{ng} / \mathrm{mL}$ for acrylamide, and the coefficient of determination $r^{2}$ was 0.9998 . The internal standard was used for the recovery test, and it varied from $95 \%$ to $103 \%$. The samples were analyzed at 0 , 4, 16 and 32 hours of heat treatmentand results were expressed as nanograms per gram of sample.

Acrylamide, [2,3,3-d $\left.\mathrm{d}_{3}\right]$-acrylamide, standard were obtained from Sigma (St. Louis, MO, USA). All of the samples were filtered through $25 \mathrm{~mm}$ diameter and 0.45 $\mu \mathrm{m}$ pore size nylon filter using a $2.5 \mathrm{~mL}$ conventional syringe (BD, Franklin Lakes, NJ) equipped with a PTFE adapter (Phenomenex, Torrance, CA, USA). Carrez reagent potassium salt and Carrez reagent zinc salt were purchased from Carlo Erba (Milano, Italy).

\subsection{Statistical Analysis}

All determinations and experiments were performed in triplicate and the results are the average values of three determinations. Analysis of variance (ANOVA) was carried out using XLSTAT 2006, version 2006.6 (ADDINSOFT, Paris, France). Differences at $P \leq 0.05$ were con- 
sidered significant.

\section{Results and Discussions}

\subsection{Biophenols}

Seed oils are generally poor of phenol compounds $[6,7]$. It was confirmed by our analytical results, whereonly 5.7 $\mathrm{mg} / \mathrm{L}$ of phenols expressed as gallic acid were found in MIX C.

With enrichment of oil in biophenols deriving from OMWW, a value of $339.8 \mathrm{mg} / \mathrm{L}$ of gallic acid was reached in fresh MIX P, an amount of about sixty times greater than the control.

During heat treatment, a reduction of phenols compounds was observed. Phenolic compounds are, in fact, sensible to high temperature. Thermal treatment of oils carried out at $180^{\circ} \mathrm{C}$ can cause a significant decrease in hydroxytyrosol- and tyrosol-like substances [11]. In our experimentation, after $36 \mathrm{~h}$ of thermo-oxidation and frying, values of 65.14 and $84.07 \mathrm{mg} / \mathrm{L}$ of total phenols were reached, respectively.

The analysis carried out by HPLC-DAD confirmed the presence of hydroxytyrosol species and other complex biophenols, such as verbascoside.

\subsection{FFA, PV and TPC}

FFA increased during heat treatment in both oils analyzed. Fried samples showed higher values than thermooxidized oils at the same treatment time, because during frying the food immersed in bath oil, frozen pre-fried potatoes, released water that contributed to hydrolysis of triglycerides.

As can be seen in Figure 1, MIX P showed lower FFA levels (normalized values) than the control (MIX C), indicating a slower production of free fatty acids during heat treatment.

$\mathrm{PV}$, expressed as meq $\mathrm{O}_{2} / \mathrm{kg}$ of oil, had an irregular trend in both oils because during the thermal treatment there is a continuous formation and decomposition of the primary products of oxidation [12].

The threshold value of TPC allowed by Italian law is $25 \%$. In all samples an increasing of TPC during heat treatment was observed. Thermo-oxidized MIX P showed TPC values lower than the control during the first 16 hours of treatment (Figure 2). This could be due to a protective rule of biophenols, that are potent antioxidants.

\subsection{Fatty Acid Composition}

Oil used in this experiment was characterized by about $60 \%$ oleic acid and $26 \%$ linoleic acid Unsaturated fatty acids (UFA)/saturated fatty acids (SFA) ratio was about

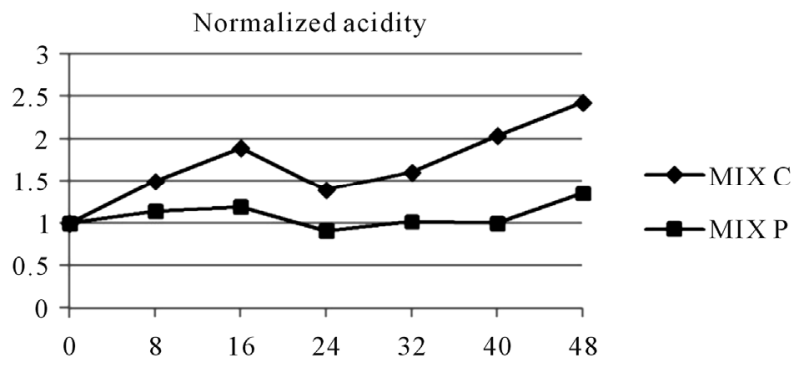

Figure 1. Normalized acidity values for thermo-oxidized oil enriched in biophenols (MIX P) and control oil (MIX C).

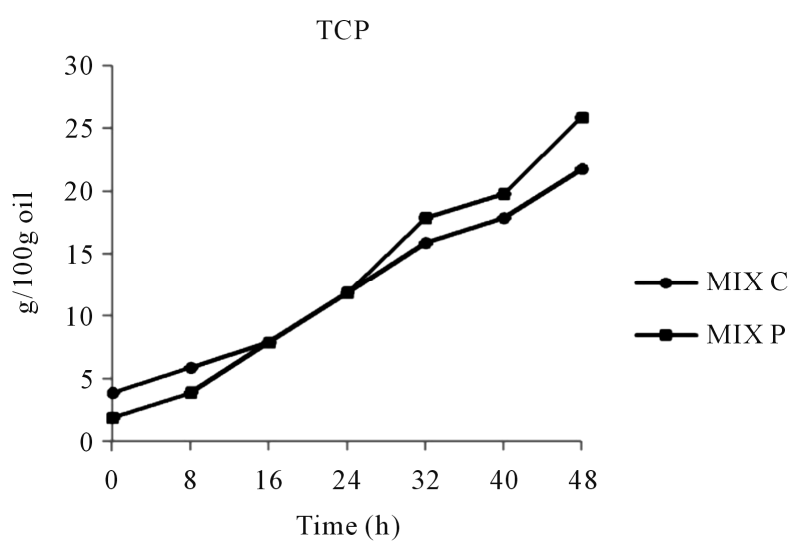

Figure 2. TPC trend during thermo-oxidation process in MIX C and MIX P samples.

$10 \%$.

During heat treatment, an increasing of octanoic acid was observed. It is known that C8:0 is formed during the oxidation of long chain fatty acids [13]. Therefore shortchain fatty acids may be used as indicators of the degree of oxidative deterioration of frying oils $[12,14]$. C8:0 was absent in fresh oils. It has been detected after $8 \mathrm{~h}$ of thermo-oxidation process in MIX C, while it was not detected in thermo-oxidized MIX P until $32 \mathrm{~h}$ of heat treatment.

UFA/SFA ratio may be also considered as oil degradation indicator. This ratio decreased during heat treatment (Figure 3). A reduction of 14\% was observed in MIX C, while a lower reduction of $0.08 \%$ was detected in MIX P.

Moreover, UFA/SFA ratio showed good correlation with TPC $\left(\mathrm{R}^{2}=0.93\right.$ for thermo-oxidized and 0.96 for frying MIX P).

\subsection{Determination of Acrylamide in Fried Potatoes}

Acrylamide is a potential human carcinogen deriving from the reaction of the amino acid asparagine and a carbonyl-containing compound at typical cooking temperatures [15]. Acrylamide concentration in chips increased during heat treatment. In fresh French fries, only 

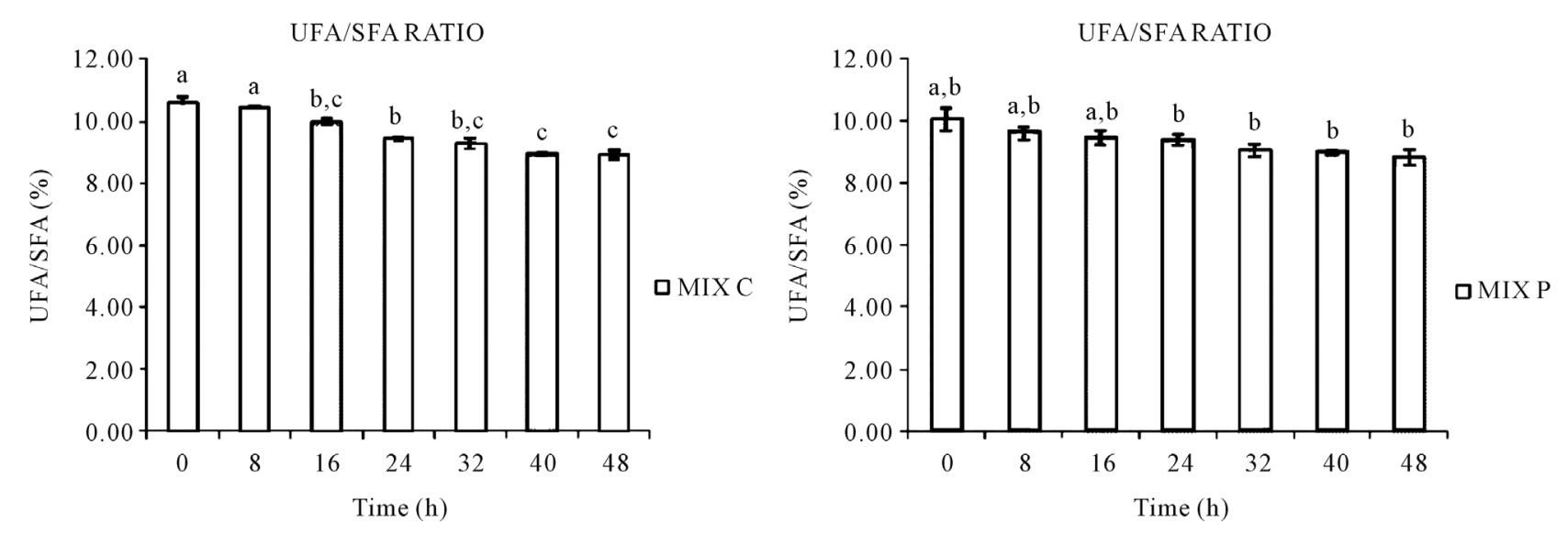

Figure 3. UFA/SFA ratio in MIX C and MIX $P$ oils. a-c: different letters for the same oil correspond to statistically significant differences $(P \leq \mathbf{0 . 0 5})$.

traces of acrylamide were detected. At $4 \mathrm{~h}$ of heat treatment, an amount of about $270 \mathrm{ng} / \mathrm{g}$ in potatoes fried in MIXC and MIXP oils was detected. After $16 \mathrm{~h}$ and $32 \mathrm{~h}$ of heat treatment, higher amount of acrylamide was detected in potatoes fried in the control oil than in potatoes fried in MIX P. As confirmed by Napolitano et al. [16], acrylamide formation was faster in oil having the lowest concentration of phenolic compounds. According to Shiyi Ou et al. [17], oxidation products are able to directly destruct acrylamide and its precursor, asparagine, thus inhibit acrylamide formation.

\section{Conclusions}

Data obtained in this study suggested that the enrichment with biophenols can improve the oxidative stability of oils.

In fact lower increase of acidity levels (normalized values), lower TPC values during the first 16 hours of treatment, absence of C8:0 until $24 \mathrm{~h}$ of treatment and lower acrylamide content were observed during heat treatment when biophenols were added to oil. On the other hand, the recovery of OMWW can be both environmental and economic disadvantages because they are highly polluting substances and require expansive disposal [18].

\section{REFERENCES}

[1] C. Gertz, S. Klostermann and S. P. Kochhar, "Testing and Comparing Oxidative Stability of Vegetable Oils and Fats at Frying Temperature," European Journal of Lipid Science and Technology, Vol. 102, No. 8-9, 2000, pp. 543551.

doi:10.1002/1438-9312(200009)102:8/9<543::AID-EJLT 543>3.0.CO;2-V

[2] E. Choe and D. B. Min, "Chemistry of Deep-Fat Frying
Oils," Journal of Food Science, Vol. 72, 2007, pp. R77R86.

[3] F. Pedreschi, P. Moyano, K. Kaack and K. Granby, "Colour Changes and Acrylamide Formation in Fried Potatoslices," Food Research International, Vol. 38, No. 1, 2005, pp. 1-9. doi:10.1016/j.foodres.2004.07.002

[4] M. Blumenthal, "A New Look at the Chemistry and Physics of Deep-Fat Frying," Food Technology, Vol. 45, 1991, pp. 68-71.

[5] F. Visioli, A. Poli and C. Gall, "Antioxidant and Other Biological Activities of Phenols from Olives and Olive Oil," Medicinal Research Reviews, Vol. 22, No. 1, 2002, pp. 65-75. doi:10.1002/med.1028

[6] A. Koski, E. Psomiadou, M. T. A. Hopia, P. Kefalas and K. W. M. Heinonen, "Oxidative Stability and Minor Constituents of Virgin Olive Oil and Cold-Pressed Rapeseed Oil," European Food Research and Technology, Vol. 214, No. 4, 2002, pp. 294-298. doi:10.1007/s00217-001-0479-5

[7] A. De Leonardis, V. Macciola and A. Di Rocco, "Oxidative Stabilization of Cold-Pressed Sunflower Oil Using Phenolic Compounds of the Same Seeds," Journal of the Science of Food and Agriculture, Vol. 83, No. 6, 2003, pp. 523-528. doi:10.1002/jsfa.1376

[8] R. Romano, A. Giordano, S. Vitiello, L. Le Grottaglie and S. Spagna Musso, "Comparison of the Frying Performance of Olive Oil and Palm Superolein," Journal of Food Science, Vol. 77, No. 5, 2012, pp. C519-C531. doi:10.1111/j.1750-3841.2012.02663.x

[9] G. Blekas, E. Psomiadou, M. Tsimidou and D. Boskou, "On the Importance of Total Polar Phenols to Monitor the Stability of Greek Virgin Olive Oil," European Journal of Lipid Science and Technology, Vol. 104, No. 6, 2002, pp. 340-346.

doi:10.1002/1438-9312(200206)104:6<340::AID-EJLT34 $0>3.0 . \mathrm{CO} ; 2-\mathrm{L}$

[10] V. Gökmen, H. Z. Şenyuva, J. Acar and K. Sarığlu, "Determination of Acrylamide in Potato Chips and Crisps by High Performance Liquid Chromatography," Journal of Chromatography A, Vol. 1088, 2005, pp. 193-199. 
[11] M. Brenes, A. Garciä, M. C. Dobarganes, J. Velasco and C. Romero, "Influence of Thermal Treatments Simulating Cooking Processes on the Polyphenol Content in Virgin Olive Oil," Journal of Agricultural and Food Chemistry, Vol. 50, No. 21, 2002, pp. 5962-5967. doi:10.1021/jf020506w

[12] E. N. Frankel, "Lipid Oxidation," The Oily Press, Dundee, 2005. doi:10.1533/9780857097927

[13] N. Andrikopoulos, N. Kalogeropoulos, A. Falirea and M. N. Barbagianni,"Performance of Virgin Olive Oil and Vegetable Shortening during Domestic Deep-Frying and Pan-Frying of Potatoes," International Journal of Food Science and Technology, Vol. 37, No. 2, 2002, pp. 177190. doi:10.1046/j.1365-2621.2002.00555.x

[14] M. C. Dobarganes, J. J. Rios and M. C. Perez-Camino, "Relaciones Entre la Composicibn de Aceites Vegetales y 10s Componentes Volatiles Producidos Durante su Termoxidacion," Grasas y Aceites, Vol. 37, 1986, pp. 61-67.

[15] D. Zyzak, R. Sanders, M. Stojanovic, B. Tallmadge, L. Eberhart, D. Ewald, C. Gruber, T. R. Morsch, M. A.
Strothers, G. P. Rizzi and M. D. Villagran, "Acrylamide Formation Mechanism in Heated Foods," Journal of Agricultural and Food Chemistry, Vol. 51, 2003, pp. 4782-4787. doi:10.1021/jf034180i

[16] A. Napolitano, F. Morales, R. Sacchi and V. Fogliano, "Relationship between Virgin Olive Oil Phenolic Compounds and Acrylamide Formation in Fried Crisps," Food Chemistry, Vol. 56, No. 6, 2008, pp. 2034-2040. doi:10.1021/jf0730082

[17] S. Y. Ou, J. J. Shi, C. H. Huang, G. W. Zhang, J. W. Teng, Y. Jiang and B. Yang, "Effects of Antioxidants on Elimination and Formation of Acrylamide in Model Reaction Systems," Journal of Hazardous Materials, Vol. 182, No. 1-3, 2010, pp. 863-868. doi:10.1016/j.jhazmat.2010.06.124

[18] E. De Marco, M. Savarese, A. Paduano and R. Sacchi, "Characterization and Fractionation of Phenolic Compounds Extracted from Olive Oil Mill Wastewaters," Food Chemistry, Vol. 104, No. 2, 2007, pp. 858-867. doi:10.1016/j.foodchem.2006.10.005 